\title{
A interface linguagem/mundo como produção simultânea: quando estudantes enfrentam a administração central em uma universidade pública
}

Bruno Deusdará (UERJ)

Décio Rocha (UERJ)

\section{Resumo}

Este artigo problematiza diferentes modos de conceber os vinculos entre o plano linguístico $e$ o extralinguístico, rejeitando qualquer anterioridade deste sobre aquele. Como referencial teórico, parte-se de Bakhtin, afirmando-se um privilégio da variação sobre a estabilidade do sentido. Com Maingueneau e Deleuze, aponta-se uma necessária reflexão sobre o tempo, ao se propor uma dinâmica de coengendramentos entre linguagem e mundo. Nas análises, privilegiam-se os embates em notícias que tematizam a inauguração de um Restaurante Universitário em instituição pública do Rio de Janeiro.

Palavras-Chave: produção de real, sentido, prática discursiva, enunciação. 


\section{Introdução}

O presente artigo tem sua motivação em um encontro intempestivo entre um interesse teórico voltado para a produção de sentido na linguagem e um evento, no mínimo, inusitado: a recente inauguração (ou teria sido um simples "teste de funcionamento", conforme se alegou mais tarde?) do Restaurante Universitário de uma universidade pública do Rio de Janeiro, momento para o qual foi convidada a "comunidade universitária", ou melhor, parte dessa mesma comunidade, uma vez que se impediu o acesso de um dos segmentos mais interessados no evento - os estudantes.

Acerca do interesse teórico indicado anteriormente, seria preciso dizer que, não obstante vasta tradição de estudos sustentar a cisão entre a dimensão verbal e aquilo que seria seu exterior, optamos por uma perspectiva discursiva a partir da qual a recusa a essa aparente cisão é correlata da afirmação de uma dinâmica de coengendramentos. Com efeito, parece-nos indispensável interrogar o que sustentamos quando optamos por apreender a relação entre o verbal e seu entorno como efeito de um processo, ao mesmo tempo, assimétrico e simultâneo.

Delineado o problema em torno do qual nos debruçamos, caberia igualmente justificar a opção pelo evento "abertura do Restaurante Universitário da Uerj". Trata-se de anunciada "inauguração" para a qual, na qualidade de docentes da referida universidade, recebêramos "convite" enviado por correio eletrônico em mala direta institucional. Tendo sido citado nominalmente no referido convite, o governador do Estado tornou-se presença esperada no evento, gerando apreensão na comunidade acadêmica e a consequente convocação de manifestação pública pelo movimento estudantil, a se realizar durante a divulgada "inauguração". Esse foi o suposto motivo do impedimento do acesso dos estudantes ao restaurante, sendo mantida sua circulação limitada a uma área exterior e distante do local da "inauguração", com a utilização de cordões de isolamento sustentados por um quantitativo considerável de funcionários da segurança da Universidade. Os conflitos resultantes desse tensionamento foram prontamente noticiados nos portais eletrônicos dos grandes jornais e em programas de rádio. No dia seguinte à abertura, nota emitida pela Reitoria da Universidade se referira ao evento como um simples "teste para o funcionamento do Restaurante Universitário". Acrescente-se que foi frustrada a expectativa de presença do governador do Estado ao evento.

\section{Objetivos e quadro teórico}

Eis alguns questionamentos que inspiram a discussão a ser encaminhada no presente artigo: que polêmicas se sustentariam a partir das tensões entre o evento "inauguração", anunciado no convite que circulara amplamente, e o evento "inauguração 
simbólica" ou "teste de funcionamento", conforme passou a declarar a nota divulgada no dia seguinte ao ocorrido? Considerando os sentidos que se afirmam ou se negam nessas polêmicas, em que medida é possível tratar do socius como produção que se realiza também por meio da linguagem? Pretendendo argumentar favoravelmente à impossibilidade de descolar a divulgação de um convite e a produção de nota oficial, textos jornalísticos e emissões radiofônicas da situação empírica que tais textos antecipam e relatam, que conceituação é preciso propor acerca do verbal e do social? Que outros problemas estariam subjacentes à conceituação proposta? De que referenciais dispomos para sustentar que a produção de sentido não reside exclusivamente nas situações empíricas, nem apenas nos textos que favorecem seus arranjos e as relatam, mas em um encontro assimétrico e simultâneo entre essas dimensões?

Já dissemos anteriormente ser possível considerar ao menos dois modos de apreensão dessa relação entre o verbal e seu entorno. Nosso intuito com o presente artigo reside em explorar a conceituação em torno dos efeitos de sentido na linguagem, considerando o social e o verbal como dimensões em constante interdelimitação.

Só aparentemente a linguagem faria referência a eventos que lhe seriam exteriores. Seu poder de representação, tomado largamente como sua principal propriedade, se ativa, produzindo um duplo apagamento: de um lado, um esquecimento de que os contornos assumidos por aquilo que se "transmite" nos textos não passam de estabilizações sempre provisórias, em permanente reconfiguração; de outro lado, um esquecimento de que a própria situação de interação verbal investe na produção do ato que a institui e se legitima no curso mesmo de sua enunciação.

Partimos de uma distinção proposta entre significado e sentido, a qual reforça a impossibilidade de sustentar a estabilidade de um significado mais básico, dito genericamente "literal", como ponto de partida de qualquer variação. Entre outros referenciais possíveis, a obra de $\mathrm{M}$. Bakhtin parece oferecer elementos importantes para o encaminhamento da discussão em tela. Tal distinção, no entanto, aponta para uma necessária teorização acerca de dois problemas: de um lado, a já referida articulação entre o linguístico e seu entorno; de outro, o problema do tempo, tendo em vista as insuficiências de uma perspectiva meramente cronológica dos eventos.

Considerando o frequente apagamento de uma reflexão conceitual mais efetiva em torno da dinâmica de engendramentos simultâneos entre o verbal e o extraverbal na tradição dos estudos da linguagem, a motivação que sustenta o presente texto nos indica a necessidade de recorrer a referenciais oriundos de outros territórios disciplinares. 


\section{Linguagem e mundo: a distinção entre significação e sentido como afirmação da vida}

Se é possível delimitar um solo conceitual a partir do qual as reflexões ora propostas emergem e ganham consistência, esse é o de uma perspectiva discursiva caracterizada, entre outros aspectos, por uma recusa da anterioridade do social frente aos textos que se produzem e que, ao menos aparentemente, a ele remeteriam. Tal recusa impulsiona a compreensão acerca dos processos de produção de sentido, evitando circunscrevê-los unicamente nas relações de oposição entre as palavras - tal como, em linhas gerais, se observou na concepção de língua como sistema de signos - ou na referência que as expressões linguísticas estabeleceriam com o estado de coisas que lhes é exterior - segundo pretenderam destacar abordagens formalistas.

Parece-nos conveniente iniciar por um trabalho negativo, explicitando os diferentes traços de um contorno que dicotomiza linguagem e mundo, encontrando pontos de contato entre abordagens historicistas e logicistas a que uma perspectiva discursiva viria se contrapor.

Em linhas gerais, a anterioridade e, em certo sentido, a naturalidade das configurações sociais em relação ao plano linguístico remetem a um senso comum que goza de intenso prestígio não apenas no âmbito das ciências da linguagem, mas também em outros campos do saber.

Com efeito, postula-se a existência de um mundo mudo e caótico que demandaria das comunidades humanas sistemas cuja propriedade essencial asseguraria a inteligibilidade e a comunicabilidade dos eventos. A esses sistemas de representação caberiam fundamentalmente duas propriedades: a de decomposição dos eventos do mundo em diversos elementos, constituindo-os em palavras que nomeiam os seres, caracterizam-nos ou os qualificam, denotam eventos e expressam circunstâncias, permitindo sua compreensão pelos indivíduos, e a de reorganização desses elementos decompostos segundo certos princípios de ordenação, assegurando a transmissão de conteúdos.

A aposta na anterioridade de um real empírico - natural e mudo, é preciso insistir - caracteriza tal concepção, considerando que os diversos elementos que compõem as formas instituídas no mundo se encontrariam em relativa instabilidade. Caberia à linguagem pôr à disposição do falante formas que tornariam harmoniosamente inteligíveis e, consequentemente, comunicáveis os eventos demasiadamente caóticos.

A dupla recusa que mencionamos anteriormente situaria as propostas de teorização acerca da produção de sentido no âmbito dos estudos do discurso em diálogo, de um lado, com os fundamentos de uma semântica de base lexical e, de outro, com as orientações formalistas de base sentencial. No entanto, além 
do necessário trabalho negativo exigido pela emergência de uma disciplina não prevista no campo do saber, espera-se ainda que a dupla recusa mencionada se institua, convocando os pesquisadores da área do discurso a um trabalho de teorização não restrito, por razões óbvias, à mera redefinição conceitual.

Entre as abordagens discursivas, observa-se, com maior frequência, o confronto com uma concepção lexical, segundo a qual o significado, sendo propriedade do signo, gozaria de certa estabilidade. O contexto exerceria papel secundário, sendo convocado apenas como possibilidade de desfazer ambiguidades. Esse papel secundário conferido ao contexto se justificaria, em perspectiva lexical, por um posicionamento em torno do significado como provocado por uma estabilidade prévia, um acordo que se manifestaria na permanência de certos traços do significado nas situações de troca verbal.

Segundo Bakhtin, a precedência da estabilidade em relação ao variável seria decorrência de uma aproximação demasiada entre o sinal e o signo linguístico. Segundo o autor, a estabilidade é característica do sinal como "entidade de conteúdo imutável", que demandaria do falante de uma língua mera identificação, daí a impossibilidade da pura "sinalidade" nas línguas humanas. $\mathrm{O}$ que torna a forma linguística signo "não é sua identidade como sinal, mas sua mobilidade específica" (BAKHTIN, 2004, p. 94).

Desse modo, o que se sustenta é a instabilidade da significação em confronto com a multiplicidade de contextos situacionais em que ocorrem. A autonomia do signo como remetendo unicamente a duas faces - a do significante e a do significado - abranda-se em favor da mobilidade das interações nas quais se inscrevem.

Considerando que "... não lidamos com a palavra isolada funcionando como unidade da língua, nem com a significação dessa palavra, mas com o enunciado acabado e com um sentido concreto: o conteúdo desse enunciado" (BAKHTIN, 2000, p. 310), a multiplicidade de significado, longe de ameaçar a unidade da palavra, é sua característica constitutiva: "a multiplicidade de significações é o índice que faz de uma palavra uma palavra" (BAKHTIN, 2004, p. 130).

Dessa forma, desloca-se, com tal discussão, o contexto de uma função complementar à dimensão constitutiva do sentido na linguagem. Os signos não poderiam comportar em si parcelas do significado do enunciado, sob o risco de considerar que, nas interações, se compartilhariam sequências de signos que justificassem compreender-lhes os significados isoladamente, em vez de enunciados dotados de um projeto de dizer e de certa expectativa de resposta.

A esse respeito, a distinção proposta por Bakhtin entre tema e significação é relevante: esta remete a "elementos da enunciação que são reiteráveis e idênticos cada vez que são repetidos" (BAKHTIN, 
2004, p. 129), enquanto aquele se refere aos contornos individuais e não reiteráveis da enunciação. "O tema da enunciação é concreto, tão concreto como o instante histórico ao qual ela pertence" (BAKHTIN, 2004, p. 129).

Tal distinção nos leva a perceber, de um lado, que não há qualquer razão para se considerar, como tradicionalmente se faz, certo conjunto de traços mais básicos de significado (sua literalidade) a que outros se juntariam. A relação com a palavra não se reduz ao mero reconhecimento de sua dimensão identitária. Disso decorreria a insistência do autor em ressaltar a compreensão como atividade responsiva. "A cada palavra da enunciação que estamos em processo de compreender, fazemos corresponder uma série de palavras nossas, formando uma réplica" (BAKHTIN, 2004, p. 132).

Com efeito, já reunimos elementos suficientes a respeito da contribuição do autor, cujas reflexões vêm sendo retomadas, desde os anos oitenta, por abordagens discursivas de base enunciativa e pragmática. Segundo Bakhtin, o tema remeteria ao sentido do enunciado como único e não reiterável, deixando à significação uma parcela ao mesmo tempo dotada de maior estabilidade e não isolável. O sentido de um enunciado efetua-se a partir de sua inscrição situacional, a que comparece sempre como resposta.

O enunciado está repleto de ecos e lembranças de outros enunciados, aos quais está vinculado no interior de uma esfera comum da comunicação verbal. O enunciado deve ser considerado acima de tudo como uma resposta a enunciados anteriores dentro de uma dada esfera (a palavra 'resposta' é empregada aqui em sentido lato): refuta-os, confirma-os, completa-os, baseia-se neles, supõe-nos conhecidos e, de um modo ou de outro, conta com eles (BAKHTIN, 2004, p. 316).

Evidenciar a presença de "ecos" e "lembranças" no enunciado corresponde a um projeto bastante forte no campo dos estudos do discurso remetendo à impossibilidade de autonomia de um texto frente a outros textos, tal qual o confirma a larga aceitabilidade do interdiscurso como um primado. Tal posição daria uma resposta contundente à suposta oposição entre literalidade e expansão da significação, advogando que a produção de sentido se sustentaria na multiplicidade de vínculos que dão consistência à rede interdiscursiva, produzidos como efeitos sempre provisórios e não como traços localizáveis.

Ainda em relação ao fragmento anterior, como não perceber certa compreensão, mesmo contrabandeada, do enunciado como remetendo a "ecos" que lhe são anteriores, mas também antecipando posicionamentos? Como deixar de ressaltar que cada enunciado, além de "congelar" sentidos recuperados em alguns já emitidos, antecipa, supõe, anuncia outros, dos quais ele próprio se torna um "eco", ainda que em potencial?

Se a dimensão histórica, em Bakhtin, é circunscrita a uma leitura do tempo como sucessão de eventos, pretendemos destacar 
acima uma outra leitura do tempo, não como sucessão de eventos organizados em sequência cronológica, mas como cortes, instantes que não cessam de abrir passado e futuro, simultaneamente. Supõe-se assim que cada ato de linguagem inaugura o instante, redefinindo passado e futuro.

Parece-nos evidente que a questão que insiste aqui apontaria para o potencial de produção de mundos na linguagem, para o qual o problema do tempo se torna debate imprescindível, uma vez que não há precedência de nenhum dos dois planos. Dessa forma, a defesa de uma dinâmica de engendramentos simultâneos entre linguagem e mundo parece passar por uma redefinição de ambos os planos, recusando conceber o mundo como plano das ações materiais e o linguístico como plano do simbólico, reduzido à representação.

\section{Práticas discursivas e produção de mundos: o caso da inauguração do bandejão da UERJ}

Desdobrando as discussões anteriores, neste item procederemos à análise do que, de maneira razoavelmente superficial, diremos tratar-se de textos que circularam em torno do evento "inauguração" do bandejão da Uerj. Se qualificamos o que dissemos antes como "razoavelmente superficial", é porque reconhecemos a enorme dificuldade em evidenciar os laços entre o verbal e seu entorno de outro modo, pretendendo eliminar qualquer possibilidade de se vislumbrar entre os dois planos a determinação de um sobre o outro. Ou seja, trata-se de evitar que se considere possível a existência de um evento como "inauguração" independente da produção de uma massa de textos: convite, confirmações, explicitações de ausências, programação, reservas, entre tantos outros. $\mathrm{O}$ esforço que empreendemos aqui se dirige exatamente sobre a explicitação dos laços de coconstrução entre o verbal e o não verbal.

Retomando o que anunciamos no início deste artigo, chamou-nos especial atenção ter havido inicialmente a circulação de um "convite" para a "inauguração" do Restaurante Universitário, em nome do governador do Estado e do reitor da Universidade, dirigido à "comunidade universitária". No dia seguinte ao ocorrido, no entanto, uma nota oficial amplamente divulgada na Universidade e citada extensamente ou na íntegra em textos da grande imprensa passa a se referir ao evento como "teste de funcionamento".

A breve retomada da tensão que neste artigo investigamos já oferece algumas indicações dos materiais considerados nas análises aqui propostas: há, inicialmente, dois modos de designar o evento em concorrência. Dessa forma, dialogamos com o imperativo metodológico em que se mantém "uma certa concepção de corpus que privilegie a perspectiva do não uno, do múltiplo" (ROCHA, 2003, p. 207). Essa opção se sustenta na ideia de que o 
interdiscurso prevalece sobre o discurso, devendo o pesquisador intervir na montagem do córpus de análise, investindo na explicitação de posicionamentos em confronto.

Considerando o propósito de problematizar os engendramentos simultâneos entre linguagem e mundo, elegemos como córpus de análise o convite para a inauguração, a nota oficial, divulgada no dia seguinte, e seis notícias, encontradas a partir de busca realizada na página eletrônica "Google", utilizando os descritores "restaurante universitário Uerj" e "bandejão Uerj". Adotaram-se os seguintes critérios para seleção das ocorrências listadas: (i) data de publicação, restringindo-nos aos textos divulgados no próprio dia do evento e no dia subsequente, e (ii) página eletrônica de origem, considerando-se os portais "oglobo. globo.com", "noticias.yahoo.com.br", "mancheteonline.com.br" e "sidneyrezende.com.br". Entre os demais resultados da busca, observamos a repetição das mesmas notícias, em outras páginas, com publicação em data posterior. Já a indicação da fonte original das notícias não se deu regularmente em todos os casos.

Inicialmente, procedemos a um levantamento dos diferentes modos de apresentar ao coenunciador o evento ocorrido, considerando como designações os grupos nominais utilizados nessas referências. Tal encaminhamento pressupõe que haja à disposição do falante um conjunto bastante diversificado de elementos linguísticos que permitem apresentar um referente ao coenunciador. Trata-se de instruções ao coenunciador que propõem a identificação de algo em determinado contexto.

No caso em análise, a referência oferece meios de apresentar a própria situação e os participantes nela envolvidos, além de argumentar sobre certa relação entre o evento "abertura do Restaurante Universitário" e a "manifestação de estudantes". A respeito da referência, trata-se de "atividade que implica a cooperação dos coenunciadores e poderá malograr, caso o coenunciador, por exemplo, se engane de referente" (MAINGUENEAU, 2001, p. 179-180).

Apresentamos inicialmente, em sua integralidade, o texto do convite que circulara por mala direta e impresso na Universidade, na semana anterior ao evento:

O Chanceler da Universidade do Estado do Rio de Janeiro, Excelentíssimo Senhor Governador Sérgio Cabral, e o Magnífico Reitor, Professor Ricardo Vieiralves, têm a honra de convidar V. Sa . para a cerimônia de inauguração do Restaurante Universitário da UERJ, a ser realizado no dia 12 de setembro de 2011, às 12h, no campus Maracanã

Vejamos a seguir alguns dos modos a partir dos quais os eventos foram apresentados nos textos em análise. Os fragmentos destacados seguem numerados nas sequências em que aparecem aqui, acompanhados da referência à fonte. 
(F1) Na segunda-feira, 12 de setembro, foi feito um teste para o funcionamento do Restaurante Universitário no campus Maracanã, com a presença de um grupo de professores, técnicos administrativos e alunos. A abertura do RU para a comunidade acadêmica acontece ainda este mês, em data a ser divulgada oportunamente. [Nota Uerj]

Em dissonância com o que fora divulgado por meio de convite com circulação virtual e impressa na Universidade, a nota oficial emitida pela Reitoria refere-se a "um teste para o funcionamento". Ressaltando o deslizamento suposto pela alternância de uma designação a outra, destaque-se o fato de que uma "inauguração" remete a "cerimônia de entrega de uma obra", "uma primeira apresentação", o "início" de algo. Uma cena de inauguração se institui, criando certa relação entre os promotores do evento (no caso, alguém que realizou uma obra pública) e os participantes, que são convidados interessados / testemunhas do que se inaugura. Já um "teste de funcionamento" não chega a pressupor rituais de formalidade esperados em uma inauguração e também não demandaria convites amplamente distribuídos. Em um teste, espera-se que os participantes escolhidos possam avaliar o sucesso ou não do empreendimento.

Se a voz oficial parece insistir em um "teste de funcionamento", o que se reitera, no entanto, nos demais textos é o signo "inauguração", como se pode observar abaixo. Tal reiteração se dará tanto na enunciação do jornalista, quanto na fala atribuída aos estudantes que participaram da manifestação, em trechos apresentados em relato:

(F2) "A inauguração no novo bandejão da Uerj, na manhã desta segunda-feira, terminou em tumulto entre vigias e estudantes." [Notícia 1]

(F3) "A estudante do $10^{\circ}$ período de História, Carolyna Barroca, de 23 anos, disse que foi uma das agredidas durante a confusão:

- A manifestação era pacífica e tomei um soco no peito de um segurança. Uma menina foi jogada no chão e várias outras apanharam. O bandejão é público e eu não posso usar. $A$ inauguração foi só para um grupo de convidados." [Notícia 1]

Como se vê, a designação "teste de funcionamento" ocorre apenas nos trechos atribuídos à voz institucional, seja através da nota na íntegra, quanto em citações dela:

(F4) "Por meio de nota, a assessoria da Universidade do Estado do Rio de Janeiro (Uerj) esclareceu na tarde desta segunda-feira que o tumulto entre estudantes e seguranças durante $u m$ teste de funcionamento do novo bandejão da universidade teria sido provocado pelos próprias manifestantes." [Notícia 2] 
Na sequência abaixo, permanece o privilégio conferido à referência à "inauguração", empregado também em sua forma verbal correlata:

(F5) "Seguranças da Uerj estão fazendo um cordão de isolamento em torno do bandejão da universidade, que foi inaugurado na manhã desta segunda-feira, para evitar que estudantes entrem no local. Mais cedo, houve tumulto entre os alunos e os vigias." [Notícia 3]

A alternância entre as duas designações mencionadas acima constitui um cenário de embate entre posicionamentos distintos, a cuja atenuação se assiste como mecanismo de emergência de certo grau de mediação, correspondendo a um ideal de notícia como "transmissão de informações" ou ainda como índice que pretenderia reforçar certa "objetividade" pressuposta em tal gênero de discurso. A referida atenuação se instituiria a partir da recuperação do signo largamente utilizado na fala dos alunos - "inauguração" - a que se passa a qualificar na expressão "inauguração simbólica":

(F6) “De acordo com a assessoria da UERJ, o bandejão começará a funcionar em menos de um mês, mas houve uma inauguração simbólica que reuniu o reitor Ricardo Vieira Alves, representantes de professores, de funcionários e de alunos" [Notícia 5]

Em F6, a presença da expressão "inauguração simbólica" parece ressaltar a existência de algum tipo de comemoração que, a despeito do esperado, não redundará em um início de funcionamento do "bandejão". Esse destaque se sustentaria na oposição indicada pela utilização da conjunção "mas", em que "começar a funcionar" se projeta como ação futura em relação à "inauguração simbólica" realizada. Tal leitura é reiterada em F7, quando "uma inauguração simbólica" é reformulada por "a comemoração":

(F7) “Uma inauguração simbólica foi realizada nesta segunda-feira, onde alunos que estariam no local queriam participar da comemoração, mas foram impedidos de entrar pelos seguranças da própria instituição". [Notícia 6]

Dessa forma, percorrer os diferentes modos de designar o evento ocorrido nos deu acesso a certos embates, opondo as vozes que sustentam ter havido "uma inauguração" sem a presença do principal segmento interessado na obra em questão - os estudantes - às que passaram a indicar a ocorrência de um "teste de funcionamento", cujo acesso limitado estaria, por consequência, justificado. Uma terceira voz parece compor o cenário, referindo-se a uma "inauguração simbólica", que, de um lado, reforçaria a existência de uma comemoração e, de outro, destacaria que tal evento não marca o início do funcionamento do "bandejão".

Ao longo da leitura das notícias, outra entrada relevante aponta para a relação proposta entre a "manifestação" e o "tu- 
multo". Percebemos que, em certos fragmentos, a "manifestação" é apresentada razoavelmente equivalente ao "tumulto":

(F8) "Menos de 100 manifestantes, muitos de fora da Uerj, fizeram uma manifestação em frente ao prédio onde está localizado o Restaurante. Alguns manifestantes, mais exaltados, foram contidos pelos seguranças depois de agredirem dois estudantes e uma funcionária da vice-reitoria, que está neste momento em atendimento médico"

Em F8, insinua-se uma correspondência entre a "manifestação" e o "tumulto", apresentando este como decorrência do tipo de movimento proposto, em que alguns "manifestantes" se encontravam "mais exaltados". Atribuir aos estudantes a categoria de "manifestantes" já supõe certa personalização dos atos em curso, uma vez que a ação de "manifestar" é tomada como atributo dos indivíduos a que se referem.

Recuperando-se o relato atribuído a estudante, explicitado em F3, ao contrário da suposta correspondência entre "manifestação" e "tumulto", o que se observa é a indicação da responsabilidade sobre o "tumulto" à agressividade dos seguranças da Universidade. Confronte com o seguinte trecho de F3: "A manifestação era pacífica e tomei um soco no peito de um segurança. Uma menina foi jogada no chão e várias outras apanharam".

Retomando o que vimos destacando até aqui, é possível observar que a referência ao teste de funcionamento parece se restringir aos fragmentos em que são apresentados relatos atribuídos à administração central da Universidade. A referência à "inauguração" é reiterada também na enunciação do jornalista. Tal recorrência vai concedendo estatuto de "informação" a esses fragmentos. A preferência por uma designação em detrimento de outra não parece ser proveniente apenas de uma escolha. Não se pode afirmar, por consequência, que tal escolha reflita uma observação mais autorizada do empírico. Interessa-nos aqui indicar a reiteração como mecanismo de produção de objetividade da notícia. Os contornos que o evento vai ganhando se fortalecem ou enfraquecem a partir da repetição de certas expressões em detrimento de outras.

(F9) "Após a inauguração do novo bandejão da Universidade do Estado do Rio de Janeiro (Uerj), na manhã de segunda-feira, ter terminado em tumulto entre vigias e estudantes, a sub-reitora de Extensão e Cultura da Uerj, professora Regina Henriques, argumentou que os preços do restaurante da universidade foram calculados a partir de uma pesquisa". [Notícia 4]

Com efeito, F9 parece evidenciar de modo bastante instigante o encontro entre diferentes vozes, cujo encadeamento promove o apagamento dos embates que vão se constituindo ao longo dos textos e no confronto entre eles.

Parece ser possível aqui aproximar o trabalho do jornalista daquele descrito por Deleuze (2007) acerca do métier do pintor. 
Apenas ilusoriamente o jornalista estaria diante da folha em branco quando se propõe a narrar um evento. Trata-se, antes, de imaginar a folha (ou a tela do computador) povoada de clichês. “Com efeito, se o pintor estivesse diante de uma superfície em branco, poderia reproduzir nela um objeto exterior que funcionaria como modelo" (DELEUZE, 2007, p. 91). Antes de preencher a tela em branco, o pintor inicia seu trabalho esvaziando-a dos clichês que a povoam:

(...) ele não pinta para reproduzir na tela um objeto que funciona como modelo; ele pinta sobre imagens que já estão lá, para produzir uma tela cujo funcionamento subverta as relações do modelo com a cópia (DELEUZE, 2007, p. 91).

No caso da notícia, os clichês parecem residir em um modo recorrente de se referir às manifestações, conferindo destaque a seus desdobramentos em detrimento dos motivos que os geram. Os clichês se atualizam e se repetem indefinidamente de uma notícia para outra. Eles emergem mesmo quando se pretende atribuir igual destaque às diferentes vozes. Vejamos o fragmento a seguir:

(F10) "A partir daí, há três versões do conflito. Em uma delas, alunos contaram que um grupo teria tentado entrar no bandejão - onde professores, funcionários e alunos convidados participavam do primeiro teste de funcionamento do bandejão." [Notícia 4]

Em F10, anunciam-se "três versões" para "o conflito". Embora se pretenda, ao menos aparentemente, conferir igual destaque às três versões, é inevitável perceber que se supõe a existência do "conflito". As polêmicas residiriam apenas nas versões. Seguindo com a leitura do fragmento em análise, observa-se a série proposta pelos alunos: inauguração, tentativa de entrada, impedimento, conflito com a segurança. Essa série parece ser contraditória com outra, atribuída à administração central da Universidade: teste de funcionamento, manifestação exaltada/conflito. Na primeira série, vê-se que o tumulto é gerado desde o impedimento da entrada dos estudantes. Na segunda, o tumulto parece decorrência natural do tipo de manifestação proposta, das atitudes exaltadas de alguns participantes.

Essas séries correm paralelas, instituem a "produção de

O discurso indireto livre corresponde a uma forma de apresentação do relato que se caracteriza por uma mistura de vozes em que "não se pode dizer exatamente que palavras pertencem ao enunciador citado e que palavras pertencem ao enunciador citante" (MAINGUENEAU, 2001, p. 153) mundos" divergentes. O que se realiza na notícia é o encontro entre essas séries, que se observa, por exemplo, na presença da expressão "teste de funcionamento", na apresentação da série atribuída aos estudantes. Se é possível restituir essa expressão como indicador da presença da voz da administração central da Universidade, tal elemento pode ser considerado como marca de uma citação em discurso indireto livre', entrelaçando-se no relato que vinha sendo atribuído aos estudantes, como se pode recuperar com o verbo "contaram". 
Pretendendo sustentar, em consonância com a hipótese de uma semântica global, a multiplicidade de sentidos em concorrência, apontamos outra entrada possível para apreensão dos diferentes embates que atravessam as notícias de jornal: as diferentes formas de apresentação do discurso relatado.

Um aspecto a ser considerado remete aos traços semânticos dos termos dicendi mobilizados:

(F11) “De acordo com Gabriel Siqueira, também estudante de História e membro do Conselho Superior de Ensino e Pesquisa, o protesto era para reclamar do valor do bandejão. Os alunos alegam que em outras instituições públicas de ensino os preços são mais baratos". [Notícia 1]

(F12) "Por meio de nota, a assessoria da Universidade do Estado do Rio de Janeiro (Uerj) informou na tarde desta segunda-feira que o tumulto entre estudantes e seguranças durante um teste de funcionamento do novo bandejão da universidade teria sido provocado pelos próprios manifestantes. Alguns deles, mais exaltados, segundo a nota, teriam agredido dois estudantes e uma funcionária da vice-reitoria. $\mathrm{O}$ texto diz ainda que dois seguranças ficaram feridos e um carro teve o vidro quebrado". [Notícia 1]

(F13) "A universidade também informou os valores a serem cobrados por refeição, questionados pelos manifestantes: estudantes cotistas pagarão $\mathrm{R} \$ 2$ pela refeição; não-cotistas $\mathrm{R} \$$ 3; e funcionários $R \$ 5,31^{\prime \prime}$. [Notícia 1]

Nos três fragmentos anteriores transcritos da notícia 1, percebem-se estatutos distintos sendo conferidos a cada uma das vozes em relato. Em F11, a voz do estudante é introduzida, modalizada a partir da expressão "de acordo com..." e através do verbo "alegar". Já a voz institucional é apresentada tanto em F12 como em F13 igualmente por modalização - "segundo a nota" - e pelo verbo "informar". Desse modo, à voz dos estudantes caberia certa posição reativa, considerando que os traços semânticos do verbo em questão apontariam para um caráter opinativo / explicativo do relato. No que tange à voz institucional, confere-se estatuto de origem da informação, atribuindo-lhe traço de "objetividade".

O que dizemos parece apenas reforçar as observações anteriores acerca do trabalho do jornalista com clichês; as oposições que se atualizam parecem não se afastar muito do esperado, quando o que se noticia é um protesto contra a medida tomada pela administração de um estabelecimento. Os fragmentos que seguem comprovam a recorrência da distribuição das vozes já observada acima, bem como o lugar conferido a cada uma delas:

(F14) "Por meio de nota, a assessoria da Universidade do Estado do Rio de Janeiro (Uerj) esclareceu na tarde desta segunda-feira que o tumulto entre estudantes e seguranças durante um teste de funcionamento do novo bandejão da universidade teria sido provocado pelos próprios manifestantes". [Notícia 2] 
(F15) "A universidade também informou os valores a serem cobrados por refeição, questionados pelos manifestantes". [Notícia 2]

(F16) "Os alunos faziam uma manifestação contra os preços das refeições - que irão custar de R \$ 2 a R \$ 5,31. Alunos alegaram ter levado socos e pontapés dos seguranças e um deles acabou com o braço arranhado. Já a Uerj informou, em nota, que os próprios manifestantes teriam agredido dois estudantes, uma funcionária e dois seguranças". [Notícia 3]

No entanto, é preciso ir além de um mero levantamento das pistas em análise, que nos levariam à evidência de diversas cenas se superpondo, em um regime de variação contínua. Tal encaminhamento nos manteria restritos a uma concepção representacional da linguagem, supondo que o evento "abertura do Restaurante Universitário" teria sido anterior à sua divulgação na imprensa e ao pronunciamento, em nota, por parte da Administração central da Universidade.

Cabe não perder de vista dois aspectos que julgamos fundamentais na argumentação favorável a uma concepção de coengendramento entre linguagem e mundo. O primeiro desses aspectos residiria em perceber que a abertura do Restaurante Universitário não se dá sem a produção simultânea de uma "massa" de textos à qual só se pode ter acesso parcialmente.

Observe-se o fragmento a seguir como exemplo do que vimos argumentando:

(F17) "Apesar dos relatos da existência de feridos, segundo a Polícia Civil, não foram registradas ocorrências da confusão nas três delegacias da região, até o final da tarde de ontem". [Notícia 3]

O que em diversas situações ganha estatuto de informação objetiva não são ações empíricas, mas tão somente encadeamento de relatos, como os que se explicitam em F17. Nesse fragmento, são retomados os relatos que indicaram haver feridos em confronto com a voz atribuída à "Polícia Civil". Essa voz se manifesta desautorizando "os relatos da existência de feridos".

Como outro exemplo, diríamos que não nos parece possível deixar de observar que a organização de cordões de isolamento, o impedimento do acesso de centenas de estudantes ao local tenha se dado sem que uma ordem, sem que conversas, orientações normativas tenham circulado. Do mesmo modo, a presença de centenas de estudantes pressupõe panfletos de convocação, mensagens de celulares, postagens em páginas eletrônicas de redes sociais, confecção de faixas, confirmações, possíveis desistências, tudo isso é produzido também por meio de textos.

Dessa forma, o problema do tempo na linguagem ganha importância quando se rejeita o senso comum em torno do qual um dado estado de coisas seria anterior aos textos que lhe fariam 
referência. Quando a relação entre linguagem e mundo é concebida em termos da anterioridade deste sobre aquela, não há outra dimensão do tempo implicada aí senão a que percebe o histórico como sucessão de presentes, aprisionando-o em uma cronologia.

Se, em Bakhtin, já havia a sensibilidade acerca de uma problematização do sentido que rejeita a primazia da estabilidade frente à variação, na perspectiva discursiva tal como vem sendo desenvolvida por D. Maingueneau, o problema do tempo parece insistir, mesmo que não esteja explicitamente indicado. Com efeito, é possível ressaltar, no conceito de prática discursiva, de D. Maingueneau (1997), a síntese, de um lado, da recusa da anterioridade do social sobre o linguístico e, de outro, da proposta de indissociabilidade entre a linguagem e a produção de modos de existência. A recusa residiria em considerar que, com a noção de prática discursiva, emerge um posicionamento a partir do qual "não se dirá ... que o grupo gera um discurso do exterior, mas que a instituição discursiva possui, de alguma forma, duas faces, uma que diz respeito ao social e a outra, à linguagem" (MAINGUENEAU, 1997, p. 55). A inflexão proposta residiria em considerar não mais os grupos em sua existência empírica exterior à linguagem, ressaltando-o sim como uma "face" da instituição discursiva. Tal é a ressalva apresentada pelo autor: "é preciso ainda deixar bem claro que visamos aos grupos que existem unicamente por e na enunciação, na gestão destes textos (...)" (MAINGUENEAU, 1997, p. 56).

A proposta que igualmente se faz com a referida noção indica uma necessária reflexão por parte do linguista em torno dos modos de organização dos grupos - passo fundamental para o reconhecimento de que o conceito de prática discursiva teria outro impacto além da mera ampliação da noção de discurso. A esse respeito, Rocha afirma que se trata de redimensionar o objeto de estudo, o qual indica uma dupla produção: "por um lado, a produção de enunciados segundo um determinado sistema de regras; por outro, o complexo institucional implicado com tal produção" (ROCHA, 1997, p. 51). Esse redimensionamento é assim avaliado como "um salto qualitativo na formulação teórica do autor: a inclusão da dimensão institucional, cuja produção se encontraria submetida às mesmas coerções que regulam os enunciados" (ROCHA, 1997, p. 52).

\section{Considerações finais}

Neste artigo, retomamos uma discussão fundamental para a constituição do campo dos estudos do discurso: a reflexão em torno do sentido na linguagem como produção. Tal debate nos coloca invariavelmente em contato com um conjunto de problemas que, em diversos momentos, foram retirados do campo dos estudos do discurso. Entre as questões tratadas, destacamos aqui a necessária reflexão sobre o social e o problema do tempo. 
Percorremos o referencial bakhtiniano com o intuito de apresentar uma concepção em torno do papel do contexto no privilégio do sentido como remetendo ao único e ao não reiterável. Tal concepção é parte imprescindível de uma teorização sobre a linguagem que se recusa a restringi-la a uma dimensão de "reapresentação" dos eventos supostamente exteriores. Considerando todo ato humano como um texto em potencial, Bakhtin oferece elementos importantes para a afirmação acerca da produção de mundos como processo que se efetua no plano linguístico e extralinguístico.

Na sequência, ao retomar a noção de prática discursiva, ressaltamos que o avanço necessário de uma teorização em torno dos vínculos entre o linguístico e o extralinguístico como planos em concorrência na produção de mundos consideraria inevitavelmente o problema do tempo. Tal problema parece merecer mais atenção, já que o que se pretende afirmar com ele é a possibilidade de criação de sentido.

Se o que se observa nesses textos, à primeira vista, é uma disputa de versões entre textos que retomam um evento passado, ainda que em uma distância de tempo consideravelmente pequena, explicitamos as considerações necessárias para afirmar que não se trata apenas de "versões", transmitindo eventos anteriores. O congelamento das forças em embate constitutivo das narrativas parece provocar um apagamento da dimensão interventiva da linguagem sobre o real, cujos contornos passamos a explorar.

Em linhas gerais, pode-se dizer que a notícia, como gênero do discurso, pretende-se à narrativa supostamente objetiva de um evento, indicando possíveis envolvidos, coordenadas de espaço e tempo, motivações presumidas, entre outros elementos. Diríamos, provisoriamente, que, ao sustentar o plano linguístico como instaurador de novos mundos, recusamos a posição segundo a qual a notícia figura como "transmissão de informação". A objetividade obsessivamente perseguida por manuais de redação dos grandes jornais seria, antes, efeito provocado por certos procedimentos enunciativos do que qualidade inerente a esses textos.

A coexistência entre o evento "inauguração" e o evento "teste de funcionamento" (ou ainda, como aparecerá em algumas notícias, "inauguração simbólica") instaura-se produzindo diferentes modos de inscrição dos participantes envolvidos, bem como formas diversas de explicitar a passagem da "manifestação" ao "tumulto".

Com efeito, a diversidade de pistas apresentadas contribui com a hipótese de que o sentido não se encontra em uma única dimensão do texto, mas as atravessa todas, em menor ou maior grau, tal como se sustenta com a hipótese de uma semântica global ${ }^{2}$. Tal modo de conceber o sentido parece permitir a aproximação entre os estudos do discurso e a filosofia de G. Deleuze, já que a variação de sentido como atualização em permanente proviso- 
riedade de formas dá expressão a forças. "O sentido é então uma noção complexa: há sempre uma pluralidade de sentidos - uma constelação, um complexo de sucessões, mas também coexistências - que faz da interpretação uma arte" (DELEUZE, 1976, p. 3).

\begin{abstract}
In this paper, we discuss different ways of conceiving the articulation between linguistic and nonlinguistic domains, refusing the point of view, which presupposes the anteriority of the latter over the former. Our theoretical basis draws from the work of Bakhtin, Maingueneau and Deleuze, in order to support three main issues: the primacy of variation over stability of sense, the concept of time and the dynamics of coengenderings between language and reality. In the analysis, we highlighted the clashes reported in different news about the inauguration of a canteen in a public university of Rio de Janeiro.
\end{abstract}

Keywords: production of reality; sense; discursive practice; enunciation.

\title{
REFERÊNCIAS
}

BAKHTIN, M. Marxismo e Filosofia da Linguagem: problemas fundamentais do método sociológico na ciência da linguagem. Trad. de Michel Lahud e Yara F. Vieira. São Paulo: Hucitec, 2004. . Estética da Criação Verbal. Trad. de Maria Ermantina Galvão. São Paulo: Martins Fontes, 2000.

. Francis Bacon: lógica da sensação. Trad. de . Rio de Janeiro: Jorge Zahar, 2007b.

Nietzsche e a filosofia. Trad. de Edmundo Fernandes Dias e Ruth Joffily Dias. Rio de Janeiro: Rio, 1976.

MAINGUENEAU, D. A gênese dos discursos. Trad. de Sírio Possenti. Curitiba: Criar, 2005.

Análise de Textos de Comunicação. Trad. de Cecília Souza-e-Silva e Décio Rocha. São Paulo: Cortez, 2001.

. Novas Tendências em Análise do Discurso. Trad. de Freda Indursky. Campinas: Pontes; Ed. da Unicamp, 1997.

ROCHA, D. "A opção por um espaço discursivo de análise: questões metodológicas". In: PAULIUKONIS, M. A. L.; GAVAZZI, S. (Org.). Texto e discurso: mídia, literatura e ensino. Rio de Janeiro: Lucena, 2003. p. 197-208. 
Produção de subjetividade: para uma cartografia dos discursos das publicações sobre videojogos. Tese (Doutorado em Linguística Aplicada e Ensino de Línguas). São Paulo: PUC-SP, 1997. 